\title{
A new method to determine optimum temperature and activation energies for enzymatic reactions
}

\author{
M. Wojcik ${ }^{1} \cdot$ J. Miłek ${ }^{1}$
}

Received: 8 February 2016/ Accepted: 21 March 2016/Published online: 11 April 2016

(c) The Author(s) 2016. This article is published with open access at Springerlink.com

\begin{abstract}
A new method for determination of the optimum temperature and activation energies based on an idea of the average rate of enzymatic reaction has been developed. A mathematical model describing the effect of temperature on a dimensionless activity for enzyme deactivation following the first-order kinetics has been derived. The necessary condition for existence of the function extreme of the optimal temperature has been applied in the model. The developed method has been verified using the experimental data for inulinase from Kluyveromyces marxianus.
\end{abstract}

Keywords Optimum temperature - Biokinetics $\cdot$ Enzyme activity · Enzyme deactivation · Kinetic parameters · Inulinase

\section{List of symbols}

a Dimensionless enzyme activity

$E \quad$ Active enzyme concentration (M)

$E_{0} \quad$ Initial active enzyme concentration (M)

$E_{\mathrm{a}} \quad$ Activation energy $\left(\mathrm{J} \mathrm{mol}^{-1}\right)$

$E_{\mathrm{d}} \quad$ Activation energy for enzyme deactivation $\left(\mathrm{J} \mathrm{mol}^{-1}\right)$

$k \quad$ Kinetic constant $\left(\mathrm{h}^{-1}\right)$

$k_{0} \quad$ Pre-exponential factor $\left(\mathrm{h}^{-1}\right)$

$k_{\mathrm{d}} \quad$ Deactivation constant $\left(\mathrm{h}^{-1}\right)$

$k_{\mathrm{d} 0} \quad$ Pre-exponential factor $\left(\mathrm{h}^{-1}\right)$

J. Miłek

jmilek@utp.edu.pl

1 Department of Chemical and Biochemical Engineering, Faculty of Chemical Technology and Engineering, University of Science and Technology, Seminaryjna 3, 85-326 Bydgoszcz, Poland

$\begin{array}{ll}P & \text { Concentration of product }(\mathrm{M}) \\ R & \text { Gas constant }\left(\mathrm{J} \mathrm{mol}^{-1} \mathrm{~K}^{-1}\right) \\ S & \text { Concentration of substrate }(\mathrm{M}) \\ t & \text { Time (h) } \\ t_{\mathrm{a}} & \text { Time of assay (h) } \\ T & \text { Temperature }(\mathrm{K}) \\ T_{\text {opt }} & \text { Optimum temperature }(\mathrm{K}) \\ \beta & \text { Parameter described Eq. }(13) \\ v & \text { Reaction rate }\left(\mathrm{M} \mathrm{h}^{-1}\right) \\ \bar{v}(T) & \text { Average reaction rate }\left(\mathrm{M} \mathrm{h}^{-1}\right)\end{array}$

\section{Introduction}

Determination of optimum temperature is commonly applied to characterize enzymes. It is based on the graph which shows the change in an enzyme's activity with increasing temperature. Both the rate of chemical reaction, as well as the rate of enzyme deactivation, increase with increasing temperature. At moderate temperatures deactivation rate is negligible and can be ignored, while the rate of enzymatic reaction increases with temperature, as for any chemical reaction.

At higher temperatures the effect of enzyme deactivation on its final activity increases. When the reaction occurs at an optimum temperature, equilibrium between these two processes is established. In many cases [1-4] the measurements of activity are made every $10^{\circ} \mathrm{C}$ and accuracy of the optimum temperature determination is limited. Some authors [5-7] demonstrate a relationship between the activity and temperature on Arrhenius diagram, and the intersection point of straight lines determines optimum temperature. Such determined optimum temperature has, 
however, limited significance since it depends upon assay duration. With increased time of assay the optimum is shifted toward lower temperatures. However, it is possible to make use of the optimum temperature for qualitative comparison of stability of enzymes from various sources, if such measurements have been carried out under identical conditions (substrate type and concentration, $\mathrm{pH}$, etc.), and within similar reaction times.

Application of optimal temperature control in a batch bioreactor enables significant reduction of the reaction time [8], or the amount of the spent enzyme [9], when compared to an isothermal process. The advantages resulting from implementation of the optimal temperature control are the greater the higher is the value of the quotient of activation energy for enzyme deactivation process and that of reaction activation. The activation energies indispensable for optimization computations are determined experimentally or calculated from the activity graph. Saqib et al. [7] made use of activity determinations of endoglucanase for the uprising part of the activity curve by applying Arrhenius diagram, while thermostability was studied by maintaining the enzyme at the predetermined temperatures. Iqbal et al. [5] employed both parts of the activity curve for glucoamylase in estimating energies of enzyme activation and deactivation, respectively. However, accounting for experimental data in the vicinity extreme of the enzyme activity leads to considerable errors in estimating activation energies.

In modeling thermal stability and activity of inulinase Santos et al. [10] utilized a concept based on accounting for effects of time and temperature on the enzymatic process. In this concept kinetic parameters are related to the reaction rate at a fixed moment of the measurement, though due to enzyme deactivation gradual decrease of the reaction rate takes place, so in fact an average value of this rate is determined.

The method of Santos et al. [10] requires additional estimation of the starting parameters based on the measurements of the deactivation rate. The aim of the present work was to develop a mathematical model that would take into account the effects of time and temperature on enzyme activity determined using the concept of the average reaction rate. The model will be verified by means of the experimental data for inulinase $[10,15]$.

\section{Theory}

During determination of the enzyme activity the experimental conditions are selected in such a way, that the effects of the substrate and product concentrations variations can be neglected. Thus the reaction rate $v$ can be described by Eq. (1) $v=-\frac{\mathrm{d} S}{\mathrm{~d} t}=\frac{\mathrm{d} P}{\mathrm{~d} t}=k E$

where $S$ is concentration of substrate, $P$ is concentration of product, $t$ is time, $k$ is kinetic constant and $E$ is active enzyme concentration.

The constant $k$ varies with temperature and can be expressed by the Arrhenius equation

$k=k_{0} \exp \left(-E_{\mathrm{a}} / R T\right)$

where $k_{0}$ is pre-exponential factor, $E_{\mathrm{a}}$ is activation energy, $R$ is gas constant and $T$ is absolute temperature.

With the increasing temperature the enzyme deactivates and this effect should be taken into account. In many cases [11-14] the rate of enzyme deactivation is approximated with the first-order kinetics leading to the following differential equation:

$\frac{\mathrm{d} E}{\mathrm{~d} t}=-k_{\mathrm{d}} E$

with an initial condition $E(t=0)=E_{0}$, where $k_{\mathrm{d}}$ is deactivation constant and $E_{0}$ is initial active enzyme concentration.

Solution of Eq. (3) yields

$E=E_{0} \exp \left(-k_{\mathrm{d}} t\right)$

A dependence between deactivation constant $k_{\mathrm{d}}$ and temperature is also given by the Arrhenius equation

$k_{\mathrm{d}}=k_{\mathrm{d} 0} \exp \left(-E_{\mathrm{d}} / R T\right)$

where $k_{\mathrm{d} 0}$ is pre-exponential factor, $E_{\mathrm{d}}$ is activation energy for enzyme deactivation.

Final expression for an instantaneous reaction rate is obtained after substituting Eqs. (2), (4) and (5) in Eq. (1)

$$
\begin{aligned}
v & =-\frac{\mathrm{d} S}{\mathrm{~d} t}=\frac{\mathrm{d} P}{\mathrm{~d} t} \\
& =k_{0} E_{0} \exp \left(-\frac{E_{\mathrm{a}}}{R T}\right) \exp \left[-\left(k_{\mathrm{d} 0} \exp \left(-\frac{E_{\mathrm{d}}}{R T}\right) t\right)\right]
\end{aligned}
$$

Depending on the applied analytical method enzyme activity is determined from the measurements of the rate of the substrate concentration decrease or by the rate of the product concentration increase. For the assay time $t_{a}$ the average reaction rate $\bar{v}(T)$ is calculated after integrating Eq. (6)

$$
\bar{v}(T)=\frac{k_{0} E_{0}}{k_{\mathrm{d} 0} t_{\mathrm{a}}} \exp \left(\frac{E_{\mathrm{d}}-E_{\mathrm{a}}}{R T}\right)\left\{1-\exp \left[-k_{\mathrm{d} 0} t_{\mathrm{a}} \exp \left(-\frac{E_{\mathrm{d}}}{R T}\right)\right]\right\}
$$

A temperature at which a maximum value of the average reaction rate has been obtained is assumed as optimal. Usually a dimensionless enzyme activity, $a$, being a quotient of the reaction rate at a given temperature and that at an optimum temperature, is applied 
$a=\frac{\bar{v}(T)}{\bar{v}\left(T_{\mathrm{opt}}\right)}$

A dependence of dimensionless activity on temperature $T$ can be expressed by the following equation

$a=\frac{\exp \left(\frac{\left(E_{\mathrm{d}}-E_{\mathrm{a}}\right)\left(T_{\mathrm{opt}}-T\right)}{R T T_{\mathrm{opt}}}\right)\left\{1-\exp \left[-k_{\mathrm{d} 0} t_{\mathrm{a}} \exp \left(-\frac{E_{\mathrm{d}}}{R T}\right)\right]\right\}}{1-\exp \left(-k_{\mathrm{d} 0} t_{\mathrm{a}} \exp \left(-\frac{E_{\mathrm{d}}}{R T_{\mathrm{opt}}}\right)\right)}$

In order for a maximum activity to be achieved the necessary condition should be fulfilled, i.e.

$\left.\frac{\mathrm{d} a}{\mathrm{~d} T}\right|_{T=T_{\mathrm{opt}}}=0$

After differentiation and substitution $T=T_{\text {opt }}$ we obtain for constant denominator

$$
\begin{aligned}
& \left(-\frac{1}{T_{\mathrm{opt}}^{2}}\right) \frac{\left(E_{\mathrm{d}}-E_{\mathrm{a}}\right)}{R} \\
& \quad \times\left(1-\exp \left(-k_{\mathrm{d} 0} t_{\mathrm{a}} \exp \left(-\frac{E_{\mathrm{d}}}{R T_{\mathrm{opt}}}\right)\right)\right) \\
& +\frac{E_{\mathrm{d}}}{R T_{\mathrm{opt}}^{2}} k_{\mathrm{d} 0} t_{\mathrm{a}} \exp \left(-\frac{E_{\mathrm{d}}}{R T_{\mathrm{opt}}}\right) \\
& \quad \times \exp \left[-k_{\mathrm{d} 0} t_{\mathrm{a}} \exp \left(-\frac{E_{\mathrm{d}}}{R T_{\mathrm{opt}}}\right)\right]=0
\end{aligned}
$$

Multiplication by $R T_{\mathrm{opt}}^{2}$ and division by $\exp \left[-k_{\mathrm{d} 0} t_{\mathrm{a}} \exp \left(-\frac{E_{\mathrm{d}}}{R T}\right)\right]$ gives

$$
\begin{aligned}
& \left(E_{\mathrm{d}}-E_{\mathrm{a}}\right)\left\{\exp \left[k_{\mathrm{d} 0} t_{\mathrm{a}} \exp \left(-\frac{E_{\mathrm{d}}}{R T}\right)\right]-1\right\} \\
& =E_{\mathrm{d}} k_{\mathrm{d} 0} t_{\mathrm{a}} \exp \left(-\frac{E_{\mathrm{d}}}{R T}\right)
\end{aligned}
$$

For further considerations it is more convenient to derive a parameter $\beta$

$\beta=k_{\mathrm{d} 0} t_{\mathrm{a}} \exp \left(-\frac{E_{\mathrm{d}}}{R T_{\mathrm{opt}}}\right)$

Combining Eqs. (12) and (13) gives

$E_{\mathrm{d}}-E_{\mathrm{a}}=\frac{E_{\mathrm{d}} \beta}{\exp \beta-1}$

After substituting Eqs. (13) and (14) into Eq. (9) we obtain

$a=\frac{\exp \left(\frac{\left(T_{\mathrm{opt}}-T\right)}{R T T_{\mathrm{opt}}} \frac{E_{\mathrm{d}} \beta}{(\exp \beta-1)}\right)\left\{1-\exp \left[-\beta \exp \left(\frac{E_{d}\left(T-T_{\mathrm{opt}}\right)}{R T T_{\mathrm{opt}}}\right)\right]\right\}}{1-\exp (-\beta)}$
Having an experimental relationship between dimensionless enzyme activity and temperature it is possible to find $T_{\text {opt }}, \beta$ and $E_{\mathrm{d}}$ directly from Eq. (15) using a non-linear regression. Rearranging Eq. (12) we get Eq. (16) which can be employed in determination of $E_{\mathrm{a}}$

$E_{\mathrm{a}}=E_{\mathrm{d}}-\frac{E_{d} \beta}{\exp \beta-1}$

\section{Results and discussion}

The elaborated method has been verified using the data for inulinase from Kluyveromyces marxianus [10, 15], which deactivates according to the first-order kinetics [10, 13, 14]. The highest activity was observed for inulinase from $K$. marxianus at $63{ }^{\circ} \mathrm{C}$ and $\mathrm{pH} 4.8$ in $0.1 \mathrm{M}$ sodium acetate buffer [10] and at $60{ }^{\circ} \mathrm{C}$ and $\mathrm{pH} 4.0$ in $0.05 \mathrm{M}$ citratephosphate buffer [15]. Constants in Eq. (15) were determined from non-linear regression by means of SigmaPlot 12.3 software.

Very high values of the regression coefficient $\mathrm{R}^{2}$ were obtained 0.984 and 0.977 for data of Santos et al. [10] and Cazetta et al. [15], respectively. The experimental data points of inulinase activity and a dependence of its activity on temperature calculated based on the estimated parameters are plotted in Figs. 1 and 2. Very good agreement between the experimental data and Eq. (15) can be seen.

The calculated values of the constants in the mathematical model [Eqs. (15), (16)] and those determined by Santos et al. [10] and Cazetta et al. [15] are given in Table 1.

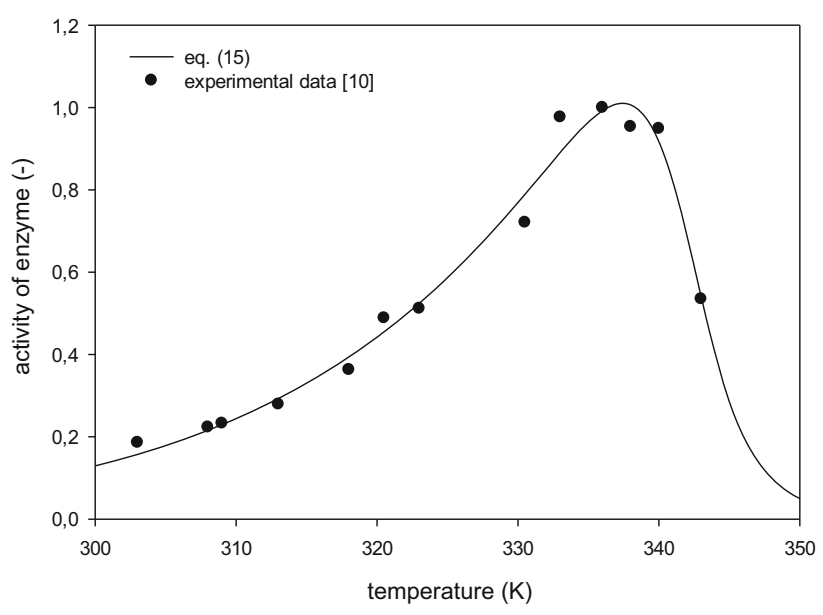

Fig. 1 Activity variation of inulinase from $K$. marxianus for estimated kinetic parameters: $T_{\mathrm{opt}}=337.27 \pm 0.26 \mathrm{~K}$, $\beta=0.2582 \pm 0.0601, E_{\mathrm{d}}=393.40 \pm 64.02 \mathrm{~kJ} \mathrm{~mol}^{-1}$ 


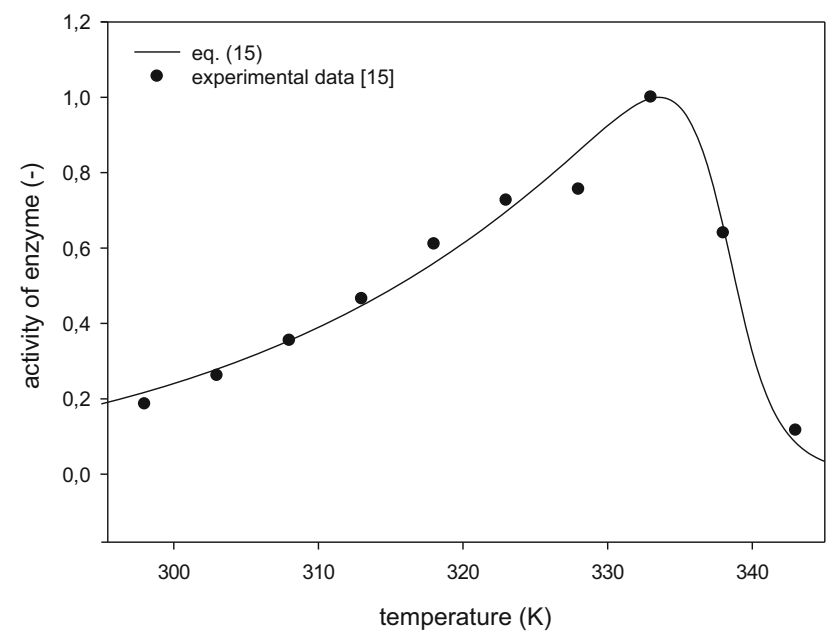

Fig. 2 Activity variation of inulinase from $K$. marxianus for estimated kinetic parameters: $T_{\text {opt }}=333.55 \pm 0.27 \mathrm{~K}$, $\beta=0.1597 \pm 0.0098, E_{\mathrm{d}}=479.74 \pm 6.15 \mathrm{~kJ} \mathrm{~mol}^{-1}$

Table 1 Values of parameters estimated from mathematical model [Eqs. (15), (16)] and those presented in literature

\begin{tabular}{lll}
\hline Figure 1 & Santos et al. [10] & Equations (15) and (16) \\
\hline$T_{\text {opt }}(\mathrm{K})$ & 336 & 337.4 \\
$E_{\mathrm{a}}\left(\mathrm{kJ} \mathrm{mol}^{-1}\right)$ & 45.1 & 48.6 \\
$E_{\mathrm{d}}\left(\mathrm{kJ} \mathrm{mol}^{-1}\right)$ & 509.3 & 393.4 \\
\hline Figure 2 & Cazetta et al. [15] & Equations (15) and (16) \\
\hline$T_{\mathrm{opt}}(\mathrm{K})$ & 333 & 333.6 \\
$E_{\mathrm{a}}\left(\mathrm{kJ} \mathrm{mol}{ }^{-1}\right)$ & - & 37.2 \\
$E_{\mathrm{d}}\left(\mathrm{kJ} \mathrm{mol}^{-1}\right)$ & - & 479.7 \\
\hline
\end{tabular}

\section{Optimum temperature}

Optimum temperature given by Santos et al. [10] at $336 \mathrm{~K}$ has been assumed based on a few experimental measurements of enzyme activity at the temperatures in the vicinity of a maximum activity of inulinase, thus the error of the optimum temperature determination did not exceed $1.5 \mathrm{~K}$. The value of the optimum temperature estimated from the model that takes into account the necessary condition for existence of function extreme is within this temperature range. The optimum temperature for inulinase from $K$. marxianus has been determined several times, and its value is between $328 \mathrm{~K}$ [16] and $343 \mathrm{~K}$ [17] when the activity measurements are performed during hydrolysis of $2 \%$ sucrose aqueous solution. The estimated value of optimal temperature for experimental data of Cazetta et al. [15] was found to be $333.6 \mathrm{~K}$ which is well within the range of values reported in the literature.

Due to lack of data on the duration time of the activity measurements, it is not possible to assess whether the observed differences are caused only by the various thermostabilities of the applied enzyme preparations. Presented computations univocally revealed that all published information concerning the effect of temperature on the enzymes activity should contain data on the duration time of activity determination. Henceforth more detailed assessment of enzyme thermostability would be possible.

\section{Activation energy $E_{\text {a }}$}

Activation energy of the reaction estimated from Eq. (16) is about $10 \%$ higher than that determined by Santos et al. [10]. This results from the fact that in the model lower increase in enzyme activation, while approaching to a maximum temperature and resulting in enhanced deactivation has been accounted for. A value of the activation energy for inulinase equals $49.7 \mathrm{~kJ} \mathrm{~mol}^{-1}$ and is within the values of 45.1 and $56.2 \mathrm{~kJ} \mathrm{~mol}^{-1}$ reported by Singh et al. [18] and Treichel et al. [14], respectively. Activation energy for inulinase prepareation used by Cazetta et al. [15] was found to be $37.2 \mathrm{~kJ} \mathrm{~mol}^{-1}$ which was a little lower than reported in the literature.

\section{Activation energy for enzyme deactivation $\mathbf{E}_{\mathbf{d}}$}

The values of the activation energy for enzyme deactivation estimated from the model were 393.4 and $479.7 \mathrm{~kJ} \mathrm{~mol}^{-1}$ for experimental data of Santos et al. [10] and Cazetta et al. [15], respectively. Mazutti et al. [19] studied directly deactivation of inulinase and have found value $343.9 \mathrm{~kJ} \mathrm{~mol}^{-1}$. Very high value of the activation energy (509.3 $\mathrm{kJ} \mathrm{mol}^{-1}$ ) determined by Santos et al. [10] is most likely overestimated since the time of enzyme halflife calculated and determined experimentally are in agreement only at $50{ }^{\circ} \mathrm{C}$. For the temperatures ranging from 52.5 to $60{ }^{\circ} \mathrm{C}$ deviations amount from 87 to $429 \%$ (Table 2 in Santos et al. [10]).

\section{Conclusions}

A new method for determination of the optimum temperature and activation energy based on a mathematical model that takes into account effect of temperature on the rate of enzyme activation and deactivation has been presented. The model has been verified using the experimental data for inulinase from $K$. marxianus. Very high value of the correlation coefficient has been obtained while the parameters estimated by means of a non-linear regression are consistent with the earlier studies.

Open Access This article is distributed under the terms of the Creative Commons Attribution 4.0 International License (http://crea tivecommons.org/licenses/by/4.0/), which permits unrestricted use, 
distribution, and reproduction in any medium, provided you give appropriate credit to the original author(s) and the source, provide a link to the Creative Commons license, and indicate if changes were made.

\section{References}

1. Sharma AD, Gill PK (2007) Purification and characterization of heat-stable exo-inulinase from Streptomyces sp. J Food Eng 79:1172-1178

2. Hmidet N, Ali NEH, Haddar A, Kanoun S, Alya SK, Nasri M (2009) Alkaline protease and thermostable $\alpha$-amylase co-produced by Bacillus licheniformis $\mathrm{NH} 1$ : characterization and potential application as detergent additive. Biochem Eng J 47:71-79

3. Yuan P, Meng K, Wang Y, Luo H, Shi P, Huang H, Bai Y, Yang $\mathrm{P}$, Yao B (2012) A protease-resistant exo-polygalacturonase from Klebsiella sp. Y1 with good activity and stability over a wide $\mathrm{pH}$ range in the digestive tract. Bioresour Technol 123:171-176

4. Kumar AG, Swarnalatha S, Kamatchi P, Sekraran G (2009) Immobilization of high catalytic acid protease on functionalized mesoporous activated carbon particles. Biochem Eng J 43:185-190

5. Iqbal Z, Rashid MH, Jabbar A, Malana MA, Khalid AM, Rajoka MI (2003) Kinetics of enhanced thermostability of an extracellular glucoamylase from Arachniotus sp. Biotechnol Lett 25:1667-1670

6. Rajoka MI, Khan S, Latif F, Shahid R (2004) Influence of carbon and nitrogen sources and temperature on hyperproduction of a thermotolerant $\beta$-glucosidase from synthetic medium by Klyveromyces marxianus. Appl Biochem Biotechnol 117:75-92

7. Saqib AAN, Hassan M, Khan NF, Baig S (2010) Thermostability of crude endoglucanase from Aspergillus fumigatus grown under solid state fermentation (SSF) and submerged fermentation (SmF). Process Biochem 45:641-646

8. Grubecki I, Wojcik M (2000) Comparison between isothermal and optimal temperature policy for batch reactor. Chem Eng Sci 55:5161-5163

9. Grubecki I, Wojcik M (2013) How much of enzyme can be saved in the process with the optimal temperature control? J Food Eng $116: 255-259$
10. Santos AMP, Oliveira MG, Maugeri F (2007) Modelling thermal stability and activity of free and immobilized enzymes as a novel tool for enzyme reactor design. Bioresour Technol 98:3142-3148

11. Tran DT, Chang JS (2014) Kinetics of enzymatic transesterification and thermal deactivation using immobilized Burkholderia lipase as catalyst. Bioprocess Biosyst Eng 37:481-491

12. Zhang Y, Xin Y, Yang H, Zhang L, Xia X, Tong Y, Chen Y, Wang W (2014) Thermal inactivation of xanthine oxidase from Arthrobacter M3: mechanism and the corresponding thermostabilization strategy. Bioprocess Biosyst Eng 37:719-725

13. Mazutti MA, Skrowonski A, Boni G, Zabot GL, Silva MF, de Oliveira D, Di Luccio M, Filho FM, Rodrigues MI, Treichel H (2010) Partial Characterization of inulinases obtained by submerged and solid-state fermentation using agroindustrial residues as substrates: A comparative study. Appl Biochem Biotechnol 160:682-693

14. Treichel H, Mazutti MA, Filho FM, Rodrigues MI (2009) Technical viability of the production, partial purification and characterization of inulinase using pretreated agroindustrial residues. Bioprocess Biosyst Eng 32:425-433

15. Cazetta ML, Martins PMM, Monti R, Contiero J (2005) Yacon (Polymnia sanchifolia) extract as a substrate to produce inulinase by Kluyveromyces marxianus var. bulgaricus. J Food Eng 66:301-305

16. de Paula FC, Cazetta ML, Monti R, Contiero J (2008) Sucrose hydrolysis by gelatin-immobilized inulinase from Kluyveromyces marxianus var. bulgaricus. Food Chem 111:691-695

17. Rouwenhorst RJ, Visser LE, Van der Baan AA, Scheffers WA, Van Dijken JP (1988) Production, distribution, and kinetic properties of inulinase in continuous cultures of Kluyveromyces marxianus CBS 6556. Appl Environ Microbiol 54:1131-1137

18. Singh RS, Dhaliwal R, Puri M (2007) Production of high fructose syrup from Asparagus inulin using immobilized exoinulinase from Kluyveromyces marxianus YS-1. J Ind Microbiol Biotechnol 34:649-655

19. Mazutti M, Ceni G, Di Luccio M, Treichel H (2007) Production of inulinase by solid-state fermentation: effect of process parameters on production and preliminary characterization of enzyme preparations. Bioprocess Biosyst Eng 30:297-304 